\title{
DETERMINAN KEJADIAN STUNTING PADA BALITA USIA 12-59
}

\section{BULAN DI KOTA PALOPO}

\section{DETERMINANTS OF STUNTING IN TODDLERS AGES 12-59 MONTHS IN PALOPO}

\author{
Resty Ryadinency ${ }^{1 *}$, Suwandi ${ }^{2}$, Try Ayu Patmawati ${ }^{3}$ \\ 1,2,3 Universitas Mega Buana Palopo. Sulawesi Selatan \\ Jln. Andi Ahmad (ex.Veteran) No. 25 Kota Palopo, Sulawasi Selatan, Indonesia \\ *Email : resty.gizi@gmail.com
}

\begin{abstract}
The problem of stunting is a picture of the socio-economic condition of the community caused by chronic nutritional conditions. One of the nutritional problems in children under five in Palopo is stunting. The stunting rate in Palopo is quite high, which generally affects children under 3 years of age spread over several sub-districts. This study aimed to identify the determinants of stunting in toddlers aged 12-59 months in Palopo. This study uses a case control design. Determination of the sample using the lameshow formula, obtained a sample of 65 cases and 65 controls in Palopo City, sampling was done by purposive sampling technique. The determinants studied were birth weight, history of ANC, maternal height, number of children under five in the family, number of family members, family income. The data were analyzed with the odd ratio value. The results showed that low birth weight $(O R=8,54)$, ANC $(O R=6,75)$, number of family members $(O R=1,07)$, family income $(O R=27,0)$ were the determinants of stunting. Mother's height $(O R=0,32)$, number of children under five in the family $(O R=0,51)$ are not determinants of stunting. There is a need for crosssectoral collaboration in efforts to prevent stunting in Palopo.
\end{abstract}

Keywords: Stunting; Toddlers; LBW; ANC; Income

\begin{abstract}
ABSTRAK
Masalah stunting adalah gambaran keadaan sosial ekonomi masyarakat diakibatkan oleh keadaan gizi kronis. Salah satu permasalahan gizi pada balita di Palopo adalah stunting. Angka stunting di Palopo cukup tinggi yang diderita pada umumnya balita di bawah 3 tahun yang tersebar pada beberapa kecamatan. Tujuan penelitian ini untuk mengidentifikasi determinan kejadian stunting pada balita usia 12-59 bulan di Kota Palopo. Penelitian ini menggunakan desain case control. Penentuan sampel menggunakan rumus lameshow didapatkan jumlah sampel 65 kasus dan 65 kontrol di Kota Palopo, pengambilan sampel dilakukan dengan teknik purposive sampling. Determinan yang diteliti adalah berat badan lahir, riwayat ANC, tinggi badan ibu, jumlah balita dalam keluarga, jumlah anggota keluarga, penghasilan keluarga. Data dianalisis dengan nilai odd ratio. Hasil penelitian menunjukkan berat badan lahir rendah $(\mathrm{OR}=8,54)$, ANC ( $\mathrm{OR}=6,75)$, jumlah anggota keluarga $(\mathrm{OR}=1,07)$, penghasilan keluarga $(\mathrm{OR}=27,0)$ merupakan determinan kejadian stunting. Tinggi badan ibu ( $\mathrm{OR}=0,32)$, jumlah balita dalam keluarga $(\mathrm{OR}=0,51)$ bukan merupakan determinan kejadian stunting. Perlu adanya kerjasama lintas sector dalam upaya pencegahan stunting di Kota Palopo.
\end{abstract}

Kata Kunci: Stunting; Balita; BBLR; ANC; Penghasilan 


\section{PENDAHULUAN}

Permasalahan gizi terutama stunting pada balita merupakan permasalahan dunia pada saat ini khususnya di negara-negera berkembang. Stunting adalah masalah kesehatan masyarakat yang prevalensinya secara antropometri menggambarkan kekurangan gizi jangka panjang dan pertumbuhan linier gagal (1). Stunting merupakan kondisi pada balita yang mengalami gagal tumbuh yang diakibatkan kekurangan nutrisi kronis terutama pada 1.000 HPK sehingga anak menjadi sangat pendek pada usianya (2). Kekurangan gizi selama masa 1000 HPK mengakibatkan gangguan kognitif dan pertumbuhan anak karena periode ini sangatlah penting bagi perkembangan otak dan pertumbuhan linier (3). Berdasarkan WHO Child Growth Standart, stunting dikategorikan pada indeks $\mathrm{PB} / \mathrm{U}$ atau TB/U dengan nilai $z$-score < -2 SD (4).

Stunting perlu mendapat perhatian khusus karena dapat menghambat perkembangan fisik dan mental ${ }^{5}$. Beberapa penelitian menunjukkan apabila pada masa balita mengalami stunting dapat meningkatkan risiko kematian anak, mempengaruhi perkembangan kognitif dan motorik, meningkatkan risiko gizi lebih, penyakit tidak menular, dan mengurangi produktivitas pada masa remaja dan berdampak jangka panjang terhadap mutu sumberdaya $(6,7,8)$.

Unicef mengatakan bahwa sekitar 1 dari 4 balita secara global mengalami stunting (9). WHO telah mencanangkan Global Nutrition Targets yang dipublikasi pada World Heatlh Assembly dimana salah satunya adalah menurunkan angka kejadian stunting sebesar 40\% pada tahun 2025 (10). Indonesia menduduki peringkat kelima prevalensi tertinggi stunting di dunia (9). Laporan Riset Kesehatan Dasar menunjukkan balita stunting di Indonesia mencapai 30,8\%. Data Pemantauan Status Gizi (PSG) Sulawesi Selatan tahun 2017, balita yang mengalami stunting sebanyak $34,8 \%$ (pendek $24,6 \%$ dan sangat pendek 10,2\%) (11). Berdasarkan data Dinas Kesehatan Kota Palopo tahun 2018, bahwa kejadian stunting berjumlah 495 balita di seluruh wilayah kerja Puskesmas yang berada di kota Palopo (12).

Stunting pada balita disebabkan beberapa faktor biasa dikaitkan dengan masalah kemiskinan diantaranya kesehatan, gizi, sanitasi serta lingkungan (13). Prediktor stunting pada bayi adalah BBLR yang akan mengakibatkan balita mengalami gangguan pertumbuhan (14). Stunting juga disebabkan kurangnya kunjungan ANC ibu selama kehamilan, kurangnya akses makanan bergizi karena pendapatan keluarga15. Banyak studi sebelumnya menekankan pentingnya sosial ekonomi, demografi, karakteristik orang tua yang berkaitan dengan status gizi balita ${ }^{16}$. Studi lain menemukan bahwa semakin banyak anggota rumah tangga dan jumlah balita dalam keluarga meningkatkan risiko stunting (17).

Penelitian ini bertujuan untuk mengidentifikasi determinan kejadian stunting pada balita usia 12-59 bulan di Kota Palopo.

\section{BAHAN DAN METODE}

Penelitian ini merupakan penelitian kuantitatif menggunakan rancangan case control. Penelitian ini dilakukan di 3 wilayah kerja Puskesmas di Kota Palopo, Sulawesi Selatan. Penentuan besar sampel dengan menggunaka rumus lameshow dengan jumlah responden sebanyak 130, digunakan perbandingan sampel 1:1 sehingga terbagi menjadi 2 kelompok responden yaitu kelompok kasus 65 responden dan kelompok kontrol 65 responden. Indikator status gizi balita berdasarkan nilai z-score $\mathrm{PB} / \mathrm{U}$ atau $\mathrm{TB} / \mathrm{U}$. Kriteria responden yang menjadi kasus adalah balita stunting usia 12-59 bulan sedangkan kriteria responden yang menjadi kontrol adalah balita yang tidak mengalami stunting dan dilakukan matching pada jenis kelamin dan tempat tinggal responden. Teknik pengambilan sampel dilakukan secara purposive sampling. Instrumen yang digunakan adalah kuesioner yang terdiri dari data demografi dan karakteristik balita dan orang tua, berat badan lahir, riwayat ANC ibu, tinggi badan ibu, sosial ekonomi (penghasilan, jumlah anggota keluarga dan jumlah balita dalam keluarga) dan pengukuran antropometri balita. Analisis data secara univariat dan bivariat dengan uji odd ratio (OR).

\section{HASIL DAN PEMBAHASAN \\ Karakteristik Balita}

Balita dengan riwayat ASI eksklusif dan umur pemberian MP-ASI masing-masing 40,8\%. Selanjutnya, status imunisasi dan riwayat kelahiran bayi masing-masing 96,2\% dan 95,4\%. Balita dengan riwayat kelahiran bayi dan berat badan lahir bayi normal masing-masing 95,4\% dan 83,1\% (Tabel 1). 
Tabel 1. Distribusi Frekuensi Karakteristik Balita

\begin{tabular}{lcc}
\hline \multicolumn{1}{c}{ Variabel } & $\mathbf{n}$ & $\mathbf{\%}$ \\
\hline $\begin{array}{l}\text { Riwayat ASI Eksklusif } \\
\quad \text { Ya }\end{array}$ & 53 & 40,8 \\
$\quad$ Tidak & 77 & 59,2 \\
$\quad \begin{array}{l}\text { Status Imunisasi } \\
\quad \text { Lengkap }\end{array}$ & 125 & 96,2 \\
$\quad$ Tidak Lengkap & 5 & 3,8 \\
Riwayat Kelahiran Bayi & & \\
$\quad$ Normal & 124 & 95,4 \\
$\quad$ Prematur & 6 & 4,6 \\
Berat Badan Lahir Bayi & & \\
$\quad$ Normal & 108 & 83,1 \\
$\quad$ BBLR & 22 & 16,9 \\
$\begin{array}{l}\text { Panjang Badan Lahir Bayi } \\
\quad \geq 48 \text { cm }\end{array}$ & 105 & 80,8 \\
$\quad<48$ cm & 25 & 19,2 \\
Usia Pemberian MP-ASI & & \\
$\quad \geq 6$ bulan & 53 & 40,8 \\
$\quad<6$ bulan & 77 & 59,2 \\
\hline$\quad$ Total & $\mathbf{1 3 0}$ & $\mathbf{1 0 0 , 0}$ \\
\hline
\end{tabular}

Karakteristik Sosial Ekonomi dan Demografi Responden

Tabel 2 menunjukkan bahwa variabel tinggi badan ibu balita yang tergolong tinggi $(\geq 150 \mathrm{~cm})$ sebesar 96,9\%. Riwayat kunjungan ANC ibu selama kehamilan 4 kali $(85,4 \%)$. Variabel pekerjaan ayah sebagai pegawai swasta $(47,7 \%)$, pekerjaan ibu sebagai IRT $(87,7 \%)$, tingkat pendidikan ayah (SMA) $(49,2 \%)$, tingkat pendidikan ibu (SMA) $(68,5 \%)$. Selanjutnya, jumlah anggota keluarga $(<5)$ dan jumlah balita dan keluarga $(\leq 2)$ masing-masing $(75,4 \%)$ dan $(68,5 \%)$. Penghasilan keluarga UMP $\geq 3.000 .000(38,5 \%)$.

Tabel 2. Distribusi Frekuensi Karakteristik Sosial Ekonomi dan Demografi Keluarga Balita

\begin{tabular}{lcc}
\hline \multicolumn{1}{c}{ Variabel } & $\mathbf{n}$ & $\%$ \\
\hline Tinggi Badan Ibu Balita & & \\
$\quad$ Tinggi & 126 & 96,9 \\
$\quad$ Pendek & 4 & 3,1 \\
Riwayat ANC & & \\
$\quad \geq 4$ kali & 111 & 85,4 \\
$\quad \leq 3$ kali & 19 & 14,6 \\
Pekerjaan Ayah & &
\end{tabular}

\begin{tabular}{|c|c|c|}
\hline Pegawai Swasta & 62 & 47,7 \\
\hline BUMN & 2 & 1,5 \\
\hline Wiraswasta & 41 & 31,5 \\
\hline Lain-lain & 25 & 19,2 \\
\hline \multicolumn{3}{|l|}{ ekerjaan Ibu } \\
\hline PNS & 4 & 3,1 \\
\hline Pegawai Swasta & 4 & 3,1 \\
\hline Wiraswasta & 2 & 1,5 \\
\hline IRT & 114 & 87,7 \\
\hline Lain-lain (Petani, Tukang & 6 & 4,6 \\
\hline \multicolumn{3}{|l|}{ Batu, Nelayan) } \\
\hline \multicolumn{3}{|l|}{ endidikan Ayah } \\
\hline SD & 2 & 1,5 \\
\hline SMP & 9 & 6,9 \\
\hline SMA & 64 & 49,2 \\
\hline D3 & 25 & 19,2 \\
\hline S1 & 54 & 41,6 \\
\hline \multicolumn{3}{|l|}{ endidikan Ibu } \\
\hline SD & 1 & 0,8 \\
\hline SMP & 9 & 6,9 \\
\hline SMA & 89 & 68,5 \\
\hline D3 & 5 & 3,8 \\
\hline S1 & 26 & 20 \\
\hline \multicolumn{3}{|l|}{ Imlah Balita dalam } \\
\hline \multicolumn{3}{|l|}{ eluarga } \\
\hline$>2$ & 32 & 24,6 \\
\hline$\leq 2$ & 98 & 75,4 \\
\hline \multicolumn{3}{|l|}{ Imlah Anggota Keluarga } \\
\hline$\geq 5$ & 41 & 31,5 \\
\hline$<5$ & 89 & 68,5 \\
\hline \multicolumn{3}{|l|}{ enghasilan } \\
\hline $\mathrm{UMP} \geq 3.000 .000$ & 50 & 38,5 \\
\hline $\mathrm{UMP}<3.000 .000$ & 80 & 61,5 \\
\hline Total & 130 & 100,0 \\
\hline
\end{tabular}

\section{Determinan Kejadian Stunting pada Balita}

Faktor determinan kejadian stunting yang dianalisis diantaranya berat badan lahir balita, riwayat ANC ibu, tinggi badan ibu, jumlah balita dalam keluarga, jumlah anggota keluarga dan penghasilan keluarga (Tabel 3). 
Tabel 3. Faktor Determinan Kejadian Stunting pada Balita (12-59 Bulan) di Kota Palopo

\begin{tabular}{|c|c|c|c|c|c|c|c|}
\hline \multirow{3}{*}{ Variabel } & \multicolumn{4}{|c|}{ Status Gizi } & \multirow{2}{*}{\multicolumn{2}{|c|}{ Total }} & \multirow[t]{3}{*}{ OR } \\
\hline & \multicolumn{2}{|c|}{ Stunting } & \multicolumn{2}{|c|}{ Normal } & & & \\
\hline & $\mathbf{n}$ & $\%$ & $\mathbf{n}$ & $\%$ & $\mathbf{n}$ & $\%$ & \\
\hline Berat Badan Lahir & & & & & & & \multirow{3}{*}{$\begin{array}{c}8,54 \\
(2,83-30,58)\end{array}$} \\
\hline Normal & 46 & 70,8 & 62 & 95,4 & 108 & 83,1 & \\
\hline BBLR & 19 & 29,2 & 3 & 4,6 & 22 & 16,9 & \\
\hline \multicolumn{7}{|l|}{ Riwayat ANC } & \multirow{3}{*}{$\begin{array}{c}6,75 \\
(1,86-24,49)\end{array}$} \\
\hline$\leq 3$ & 16 & 24,6 & 3 & 4,6 & 19 & 14,6 & \\
\hline 4 & 49 & 75,4 & 62 & 95,4 & 111 & 85,1 & \\
\hline \multicolumn{7}{|l|}{ Tinggi Ibu } & \multirow{3}{*}{$\begin{array}{c}0,32 \\
(0,33-3,19)\end{array}$} \\
\hline Tinggi & 64 & 98,5 & 62 & 95,4 & 126 & 96,9 & \\
\hline Pendek & 1 & 1,5 & 3 & 4,6 & 4 & 3,1 & \\
\hline \multicolumn{7}{|l|}{ Jumlah Balita } & \multirow{3}{*}{$\begin{array}{c}0,51 \\
(0,23-1,16)\end{array}$} \\
\hline$>2$ & 20 & 30,8 & 12 & 18,5 & 32 & 24,6 & \\
\hline$\leq 2$ & 45 & 69,2 & 53 & 81,5 & 98 & 75,4 & \\
\hline \multicolumn{7}{|l|}{ Jumlah Anggota } & \multirow{4}{*}{$\begin{array}{c}1,07 \\
(0,51-2,25)\end{array}$} \\
\hline Keluarga & & & & & & & \\
\hline$>5$ & 20 & 30,8 & 21 & 32,3 & 41 & 68,5 & \\
\hline$\leq 5$ & 45 & 69,2 & 44 & 67,7 & 89 & 31,5 & \\
\hline \multicolumn{7}{|l|}{ Penghasilan } & \multirow{3}{*}{$\begin{array}{c}27,0 \\
(9,42-77,42)\end{array}$} \\
\hline $\mathrm{UMP} \geq 3.000 .000$ & 5 & 7,7 & 45 & 69,2 & 50 & 38,5 & \\
\hline $\mathrm{UMP}<3.000 .000$ & 60 & 92,3 & 20 & 30,8 & 80 & 61,5 & \\
\hline Total & 65 & 100,0 & 65 & 100,0 & 130 & 100,0 & \\
\hline
\end{tabular}

Berat badan lahir rendah ditandai dengan kurangnya berat badan bayi pada saat lahir $<2500$ gram. Pada penelitian ini, balita dengan riwayat berat badan lahir rendah $29,2 \%$. Hasil uji odd ratio (Tabel 3) menunjukkan bahwa bayi dengan riwayat BBLR memiliki 8,54 kali berisiko mengalami stunting. Dari penelitian juga ditemukan bahwa ada balita yang memiliki riwayat berat badan lahir normal tetapi mengalami stunting. Bayi dengan riwayat berat badan lahir rendah telah terbukti memiliki gangguan pertumbuhan dalam kandungan, baik akut maupun kronis. Oleh karena itu, anak-anak dengan BBLR rentan terhadap infeksi seperti diare dan infeksi saluran pernapasan, serta kehilangan nafsu makan dibandingkan dengan anak-anak dengan berat badan lahir normal ${ }^{18}$. Hubungan berat badan lahir terhadap stunting terjadi pada 6 bulan pertama kehidupan, kemudian menurun hingga usia 24 bulan. Dengan demikian, jika bayi dapat mengejar ketertinggalannya dalam 6 bulan pertama kehidupan, ada kemungkinan bayi dapat mencapai tinggi badan normal (19). Penelitian ini sejalan dengan penelitian yang dilakukan di Puskesmas Puuwatu Kota Kendari yang menunjukkan bawah riwayat BBLR merupakan determinan kejadian stunting (20).

Beberapa Puskesmas di Kota Palopo memilki kebijakan masing-masing dalam penanganan masalah stunting yaitu dengan pemberdayaan tenaga kesehatan dan dibantu oleh kader dalam memotivasi ibu hamil untuk melakukan kunjungan ANC. Berdasarkan hasil penelitian riwayat ANC memiliki 6,75 kali risiko stunting (Tabel 3), salah satu faktor penyebab stunting adalah BBLR yang disebabkan oleh ibu hamil yang mengalami KEK. Ibu hamil KEK disebabkan karena kurangnya kunjungan ANC selama kehamilan (21). Tinggi badan ibu dan jumlah balita dalam keluarga bukan merupakan determinan stunting karena hasil penelitian menunjukkan bahwa sebagian besar pada kelompok kasus tinggi badan ibu normal dan jumlah balita dalam keluarga $\leq 2$, hal ini kemungkinan adanya faktor internal maupun eksternal lain seperti penyakit infeksi atau asupan gizi sejak dini pada balita. Tingkat ekonomi tidak lepas dari tingkat penghasilan keluarga.

Penghasilan keluarga merupakan determinan stunting $(\mathrm{OR}=27,0)($ Tabel 3), penghasilan keluarga merupakan faktor yang menentukan kualitas dan kuantitas asupan nutrisi pada keluarga. Tingkat penghasilan merupakan faktor yang menentukan kualitas dan kuantitas makanan. Penghasilan yang 
tinggi berpengaruh terhadap perbaikan nutrisi dan kesehatan dalam rumah tangga. Penelitian ini sejalan dengan penelitian yang dilakukan di Kota Semarang $(\mathrm{OR}=5,39)$, penghasilan keluarga yang rendah mengakibatkan rendahnya daya beli keluarga sehingga berpengaruh terhadap perbaikan gizi khususnya bagi anak (22). Jumlah anggota keluarga $>5$ memiliki 1,07 kali berisiko pada kejadian stunting. Salah satu permasalahan ekonomi ada banyaknya anggota keluarga dalam satu rumah, penelitian terdahulu menunjukkan bahwa bahwa kemungkinan peningkatan stunting terjadi pada anak-anak dari status keluarga miskin dan menengah akibat ketidakmampuan dalam membeli makanan bergizi serta jumlah anggota keluarga yang banyak (23).

\section{KESIMPULAN DAN SARAN}

Stunting merupakan masalah kesehatan masyarakat yang terjadi di Kota Palopo. Riwayat berat badan lahir bayi, anternatal care, jumlah anggota keluarga dan penghasilan keluarga merupakan determinan stunting pada balita. Oleh karena itu, perlu adanya kerjasama lintas sektor dalam mengatasi masalah stunting khususnya dalam peningkatan ekonomi masyarakat untuk pemenuhan nutrisi balita. Bagi ibu dalam perencanaan kehamilan agar memperhatikan asupan nutrisi serta pemeriksaan kehamilan rutin untuk mencegah berat badan lahir rendah pada bayi.

\section{UCAPAN TERIMAKASIH}

Peneliti mengucapkan terima kasih kepada Direktorat Jenderal Penguatan Riset dan Pengembangan Kementerian Riset dan Teknologi/Badan Riset dan Inovasi yang telah memberikan dana riset skim Penelitian Dosen Pemula tahun anggaran 2020.

\section{DAFTAR PUSTAKA}

1. Cruz, L.M.G; Azpeitia, G.G; Suarez, D.R; Rodriguez, A.S; Ferrer, J.F.; Majem, L.S. Factors associated with stunting among children aged 059 months from the Central region of Mozambique. Nutrient, 2017; 9,491

2. Ramayulis; Kresnawan; Iwaningsih; Rochani. Stop Stunting dengan Konseling Gizi. Jakarta Penebar Plust, 2018.

3. Onis M; Dewey, K.G; Borghi, E; Onyango, A.W; Blossner, M; Daelmans, B; Branca, E. The World Health Organization's global target for reducing childhood stunting by 2025: Rationale
4. Nutrition Landscape Information System (NLSI) country profile indicators: interpretation guide. Geneva: World Health Organization; 2010.

5. Purwandini K, Kartasurya MI. Pengaruh pemberian micronutrient sprinkle terhadap perkembangan motorik anak stunting usia 12-36 bulan. Journal of Nutrition College, 2013; Volume 2 Nomor 1 Halaman 147-163.

6. Brinkman, H.J; dee Pee, S; Sanogo, I. High food prices and the global financial crisis have reduced access to nutritious food and worsened nutritional status and health. J Nut, 2010; 140, 153S-161S.

7. Martorell R; Horta BL; Adair LS. Consortium on health oriented research in transitional societies group. Weight Gain in the First Two Years of Life Is an Important Predictor of Schooling Outcomes in Pooled Analyses from Five Birth Cohort From Low and Middle Income Countries. J Nutr, 2010; 140, 348-354.

8. Black, R.E; Victoria, C.G; Walker, S.P; Bhutta, Z.A; Christian, P; de Onis, M, et al. Maternal and child undernutrition and overweight in low-income and middle-income countries. Lancet 2013, 382, 427-451.

9. UNICEF. Improving child nutrition, the achievable imperative for global progress. New York: United Nations Children's Fund, 2013.

10. World Health Organization. Global nutrition targets 2025: stunting policy brief. Geneva, 2012. Available from: http//www.who.int/nutrition/topics/globaltarg ets_stunting_policybrief.pdf

11. Riskesdas. Riset Kesehatan Dasar: Laporan Nasional 2018. Badan Penelitian dan Pengembangan Kementerian Kesehatan RI; 2018.

12. Dinas Kesehatan Kota Palopo. Data kejadian stunting tahun 2018-2019. Dinkes Kota Palopo; 2018.

13. Astutik, Rahfiludin, Aruben. Faktor risiko kejadian stunting pada anak balita usia 24-59 bulan. Jurnal Kesehatan Masyarakat, 2018; 6(1).

14. Torlesse, H; Cronin, A.A; Sebayang, S.K; Nandy, R. Deeterminants of stunting in Indonesian children: evidence from a cross-sectional survey indicate a prominent role for the water, sanitation and hygiene sector in stunting reduction. BMC Public Health, 2016; 16(669).

15. Kementerian Desa, Pembangunan Daerah Tertinggal, dan Transmigrasi. Buku saku desa 
dalam penanggulangan stunting. Jakarta: Kementerian Desa, Pembangunan Daerah Tertinggal dan Transmigrasi Republik Indonesia; 2017.

16. Ntenda PAM, Chuang YC. Analysis of individuallevel andcommunity-level effects on childhood undernutrition in Malawi.Pediatrics and Neonatology. 2018; 59 (4): 380-9.

17. Budge S, Parker AH, Hutchings PT, Garbutt C. Environmental entericdysfunction and child stunting. Nutrition Reviews. 2019; 77 (4): 240-253.

18. Rahman MS, Howlader T, Masud MS, Rahman ML. Association of low-birth weight with malnutrition in children under five years in Bangladesh: do mother's education, socioeconomic status, and birth interval matter? PLoS One. 2016;11:0157814.

19. Lestari ED, Hasanah F, Nugroho NA. Correlation between non-exclusive breastfeeding and low birth weight to stunting in children. Paediatrica Indonesiana. 2018; 58 (3): 123-7.

20. Palino IL, Majid R, Ainurafiq. Determinan kejadian stunting pada balita usia 12-59 bulan di wilayah kerja Puskesmas Puuwatu Kota Kendari tahun 2016. Jimkesmas. 2017; 2(6): 250-731X.

21. Khoeroh H, Indriyanti D. Evaluasi penatalaksanaan balita stunting di wilayah kerja Puskesmas Sirampog. Unner Journal of Public Health. 2017; 6(3): 189-195.

22. Candra A, Subagio HW, Margawati A. Determinan kejadian stunting pada bayi usia 6 bulan di Kota Semarang. Jurnal Gizi Indonesia. 2016; 4(2): 82-88.

23. Tariku A, Biks GA, Derso T, Wassie MM, Abebe SM. Stunting and its determinant factors among children ages 6-59 months in Ethiopia. Italian Journals of Pediatrics. 2017; 43:112. 